\title{
Analysis of how Family and School Conditions of Left- behind Children in Yunnan Province, China Affect their Psychological Health
}

\author{
Wei Cai \\ Raffles Institution, Singapore \\ caiweivi@gmail.com
}

\begin{abstract}
The worsened psychological conditions of rural left-behind children have become a significant concern in Chinese society. This paper investigates the left-behind children's families and the school environment in which they receive education, in Yunnan Province, China. This isa large and under-privileged group, and the paper seeks to shed light on how their mental health is affected by these circumstances. The research conducted mainly employs a qualitative methodology of observation as well as analysis of quantitative data collected by sociologists and researchers. The results demonstrate that various conflicts in these situations could adversely influence their emotions and psychological health. These conclusions could inform migrant families as well as schools on ways to improve their parenting and teaching skills to better cater to the emotional needs of leftbehind children in Yunnan Province.
\end{abstract}

Keywords: Left-behind Children, Psychological Health, Yunnan, China, Migrant Workers

\section{INTRODUCTION}

Migrant workers, defined as workers holding a rural household registration (Hukou) who are employed in an urban workplace and reside in an urban area for more than six months (China Labour Bulletin, 2019), were estimated to at 288.4 million citizens in 2018.This number makes up 36 percent of the entire worker population in China (Report on China's Migrant Population Development, 2016). The large-scale movement of rural labour in search of better employment opportunities to China's developed industrial regions, such as the Pearl River Delta Region, the Yangtze River Delta Region and Beijing-Tianjin-Hebei Region, has significantly contributed to continuous economic growth and poverty reduction in China. However, given the restrictions imposed by the household registration system upon non-registered residents' access to public education and other social services in cities, as well as the higher consumption levels and prohibitively exorbitant housing prices in the urban regions, it is not uncommon for children of migrant workers, a disadvantaged group known as left-behind children (LBC), to remain in the countryside, physically separated for a long period of time from one or both of their parents. According to the 2015 1\% National Sample Survey of Population, the total number of children of migrant workers was around 103 million, out of which 66.8\% were left behind, constituting a shocking 68.8 million people (National Bureau of Statistics, 2016).

Meanwhile, research into the psychological conditions and mental health of children under 16 years old is gaining popularity and momentum in the academic field in recent years. Child psychology is the study of the behaviors and psychological processes of children and how these processes differ from adults' psychological functioning (Encyclopaedia Britannica, 2012). Childhood, a crucial period in the developmental years of an individual's mentality, exerts significant impact on the formation of lifelong behaviors and ideas (Wang et al, 2019). In China, the number of children diagnosed with psychological issues is on the rise; a survey by Shanghai 
Analysis of how Family and School Conditions of Left-behind Children in Yunnan Province, China Affect their Psychological Health

Mental Health Center suggested that 27\% secondary school students reported mental disorders; in Shenzhen, the rate is $32 \%$. In rural areas the numbers are even more staggering, with $32.5 \%$ of children diagnosed with depression (Zhang et al, 2016). The mental health of children in China has thus become an imperative and worrying issue that needs to be examined and resolved.

Caught in between the two alarming issues of labor migration and increasing psychological challenges in children are the left-behind children facing mental problems. According to research conducted in Northwestern China on the mental health of left-behind children, children from migrant households performed worse psychologically when compared to children from non-migrant households (Shi et al, 2016). The surveyed LBC's MHT ${ }^{1}$ score increased by 1.43 , the $\mathrm{SASC}^{2}$ score increased by 0.32 , and the $\mathrm{SES}^{3}$ score decreased -0.17 . These statistics reveal much severer anxiety and lower self-esteem in rural left-behind children (Table 1.1). Research also revealed that LBC exhibited worse performance in all five negative feelings commonly diagnosed among children (Table 1.2), notably dissatisfaction, loneliness, and anxiety. The percentages of LBC and non-LBC affected differ by more than 5\% (Zhang et al, 2015). Parents' company and guidance prove to be of ultimate importance for the young impressionable mindsof children. Hence,the absence of parental figures to intervene in children's psychological development processes is detrimental and constitutes a predicament that is hardly rectifiable by school intervention. Furthermore, the lack of funding and manpower puts enormous strain on teachers in rural areas and disables them from conducting personalized counselling sessions for students.

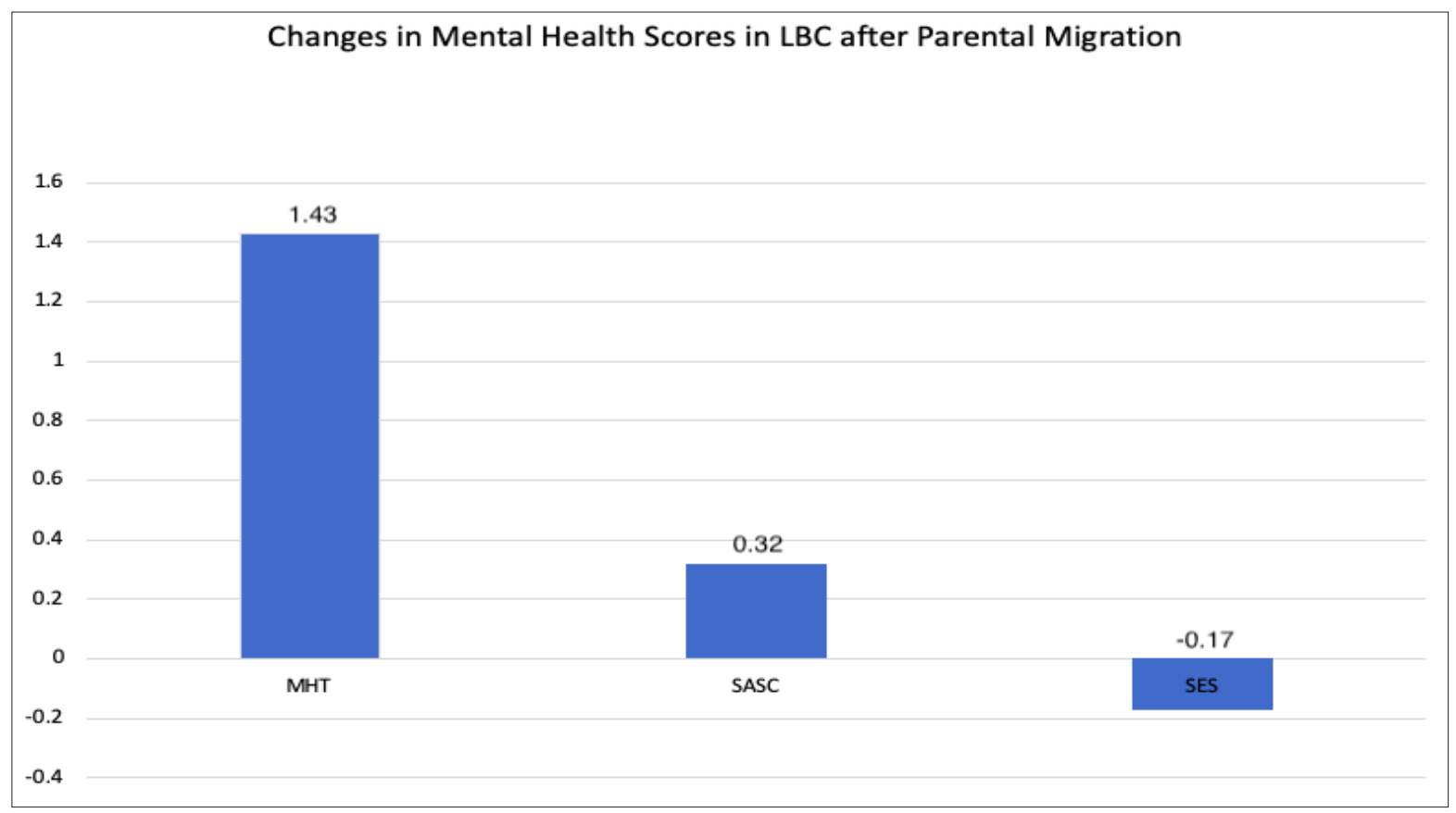

Figure1.1. Changes in mental health scores in LBC after parent(s) leave for the city (Shi et al, 2016).

1 "Mental Health Test," developed by Zhou Bucheng, a Professor from East China Normal University, is a scale used to measure general anxiety and social anxiety, where a higher score correlates with a higher risk of mental problems.

2"Social Anxiety Scale for Children" has proved credible in examining a child's emotional and cognitive issues arising from social anxiety. A higher score is suggestive of a higher degree of social anxiety.

3 The "Rosenberg Self-Esteem Scale" is a ten-item scale that assess self-worth by requiring respondents to report both positive and negative self-feelings. A higher score indicates a higher level of self-esteem. 
Analysis of how Family and School Conditions of Left-behind Children in Yunnan Province, China Affect their Psychological Health

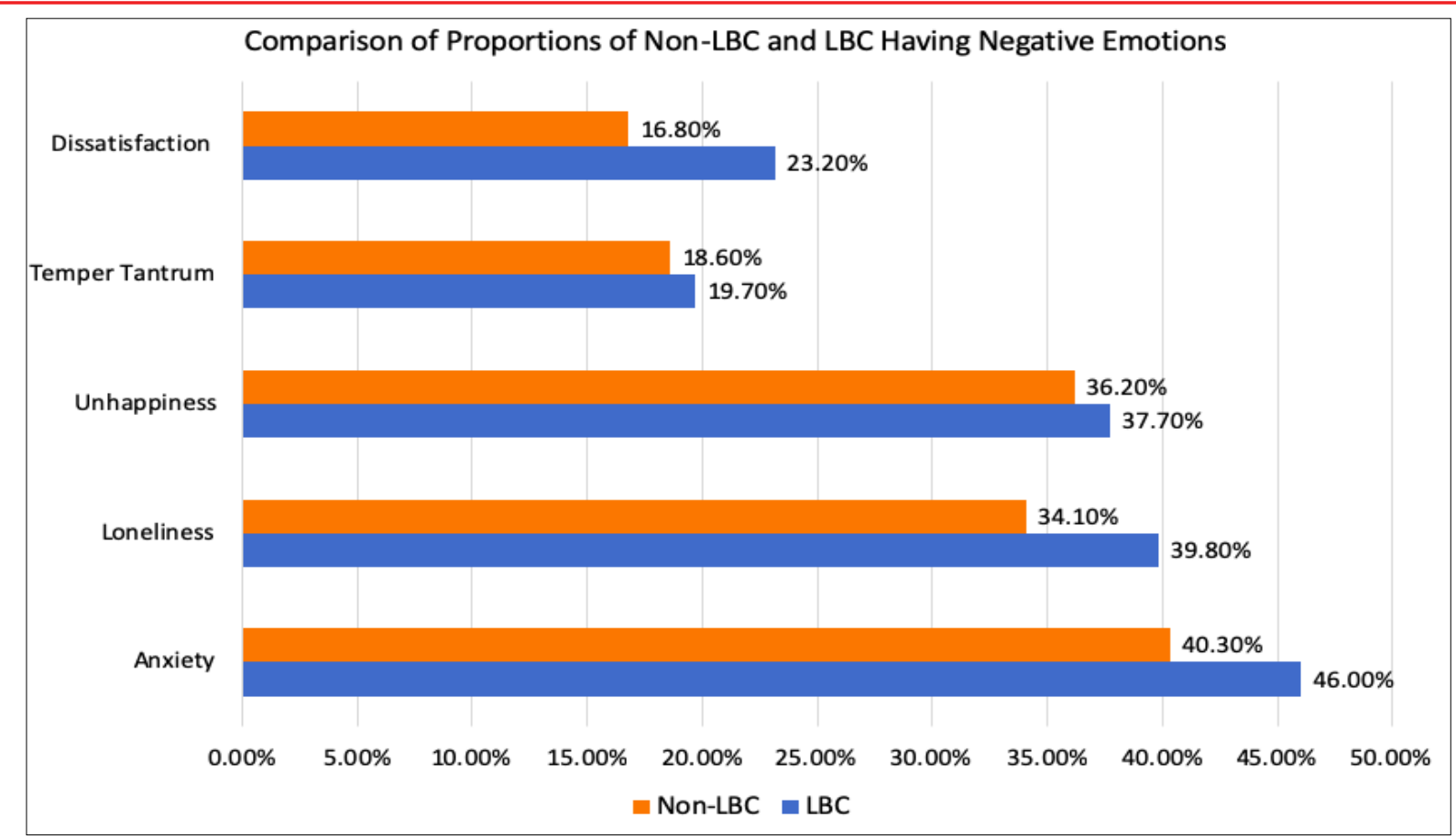

Figure1.2. Comparison of percentages of children having negative emotions (Zhang et al, 2015).

Characterised by its borders with Laos, Myanmar, and Vietnam, its diverse ethnic minorities, its mountainous areas, and its slow economic development, Yunnan, a poverty-stricken province in Southwestern China, witnesses some of the most challenging situations for its left-behind children, who amounted to more than 1.2 million people in 2018. LBCs therefore makes up 8.9\% of the total population of children ranging from 0 to 17 years in the province (Dong et al, 2013). LBCs live across 16 prefectures and cities in Yunnan Province, but they are unevenly concentrated in populous rural areas and 32\% of them are separated from their parents by the time they reach six years of age (Du et al, 2008). It is a region on which more research needs to be done to provide more informative revelation to bring about favorable changesto the living condition of the local children. Therefore, this research paper aims at investigating the psychological status of left-behind children by conducting a contextual analysis ofhow their two major environments - family and school -heavily influence their mental health.

\section{LITERATURE REVIEW}

There are already substantial research papers focusing on the mental health of left-behind children in China's frontier regions, where a stagnant economy drives millions of rural labourers to developed cities, leaving underprivileged children to cope with the enormous psychological challenge of not having parental figures. These studies have highlighted the fact that these underprivileged children score significantly lower than their non-left-behind counterparts in positive cognition and resilience (Dong et al, 2013). Researches have also discovered that left-behind children suffer in the development of relevant skills (Gao et al, 2019), lack confidence (Zhou et al, 2005)and report higher rates of depression (Xiao et al, 2019).

However, previous research has neglected to explain the underlying reasons that contribute to the children's deteriorated mental conditions. In particular, scholarship on trends related to left-behind children lacks contextual perspectives on the circumstances surrounding children's upbringing. A large proportion of extant research drew conclusions from one sample region or province, rendering the general results neither 
Analysis of how Family and School Conditions of Left-behind Children in Yunnan Province, China Affect their Psychological Health

representative nor applicable to the investigation and explanation of left-behind children's psychological conditions in Yunnan province, given the heterogeneous nature of the LBC population across China. Moreover, most previous research has targeted the effects of parental migration effect on children who accompany their parents to Chinese cities. Studies have revealed valuable information about how the children of migrant workers struggle integrating into their new environments, but it says little about the consequences for the LBC population. This paper tries to fill a critical gap in the research by examining the psychological health of leftbehind children in Yunnan.

Nonetheless, previous research has been invaluable in informing and guiding this paper and, more specifically, in analysing the inherent problems of the domestic and school environments that prominently shape left-behind children's mentality. It should be noted that the discussions below are largely qualitative-oriented. Despite the extensive use of data, some of the claims need to be further substantiated by statistical evidence. Therefore, the findings are neither exhaustive nor definite in nature. This paper, however, supplements existing literature and attempts to offer a new perspective in the discussion regarding the nationwide migration of labor and its implicationson Chinese society.

\section{ANALYSIS AND DISCUSSIONS}

\section{Family Environment}

It is a truth universally acknowledged that a child's domestic situation plays an indispensable role in his/her progressive trajectory from infanthood to adulthood. Parental education undeniably is one of the most crucial pillars in a child's mental development. To examine left-behind children's psychology, an investigation into their family condition should be of utmost imperative and importance.

\section{Absence of Maternal and/or Paternal Role}

A complete family structure, as defined by some sociologists, should be triangular, with the three sides being the father, the mother, and the child (Fei, 2008). Connubiality is premised on parent-child relationships as the latter is necessitated by the former. Parental support is an essential aspect in children's physical and mental health, andtheir supervision and guidance are undoubtedly conducive for the cultivation of morality. Longer periods spent with parents, particularly with mothers who possessa higher educational degree, is associated with a decrease in prevalence of mental problems in adolescents (Meyrose et al, 2018). However, children growing up in an unsteady domestic environment where the stable family structure is impaired by the absence of a maternal and/or paternal role, constantly feels insecure. According to a survey by the non-governmental organisation On the Way to School in 2014, some 15\% of left-behind children could be separated with their parents for one whole year without seeing each other, even during Chinese New Year (China Youth News, 2017). The desperate situation did not improve much when the survey was repeated in 2017. Telephone contact is also insufficient. According to a survey, only $46 \%$ percent of left-behind children in Yunnan frequently contact their parents (Dong et al, 2013). A quantitative investigation of the status of rural LBC suggested that the social support LBC gain from their mother and father are $41.54 \%$ and $30.38 \%$ respectively (Table 3.1), while the support that non-left-behind children obtain are $52.92 \%$ and $43.02 \%$, a stark 10 percent difference that could not be compensated by a 7\% increase in grandparental support (Zhang et al, 2015). Unavailability of support from the mother and the father culminates in various negative experiences and perceptions of LBC (Zhang et al, 2015), and $41.7 \%$ LBC develop introversion and $34.6 \%$ worry about the loss of parents' love (Table 3.2). In addition, parents usually serve as an indispensable bridge of communication between children and their teachers in school for the positive effect exerted by teachers to be maximized. Parents' disengagement from the cooperation between school and family undermines teachers' influence, subsequently strengthening the roles of peers and media. By possibly exposing left-behind children to unregulated information, this trend 
Analysis of how Family and School Conditions of Left-behind Children in Yunnan Province, China Affect their Psychological Health

might prompt unfavourable behavioural change (Ning, 2017). Stuck in the predicament between hands-on parenting and providing for their children financially, absent parents unavoidably become a hidden threat for their children's psychological health.

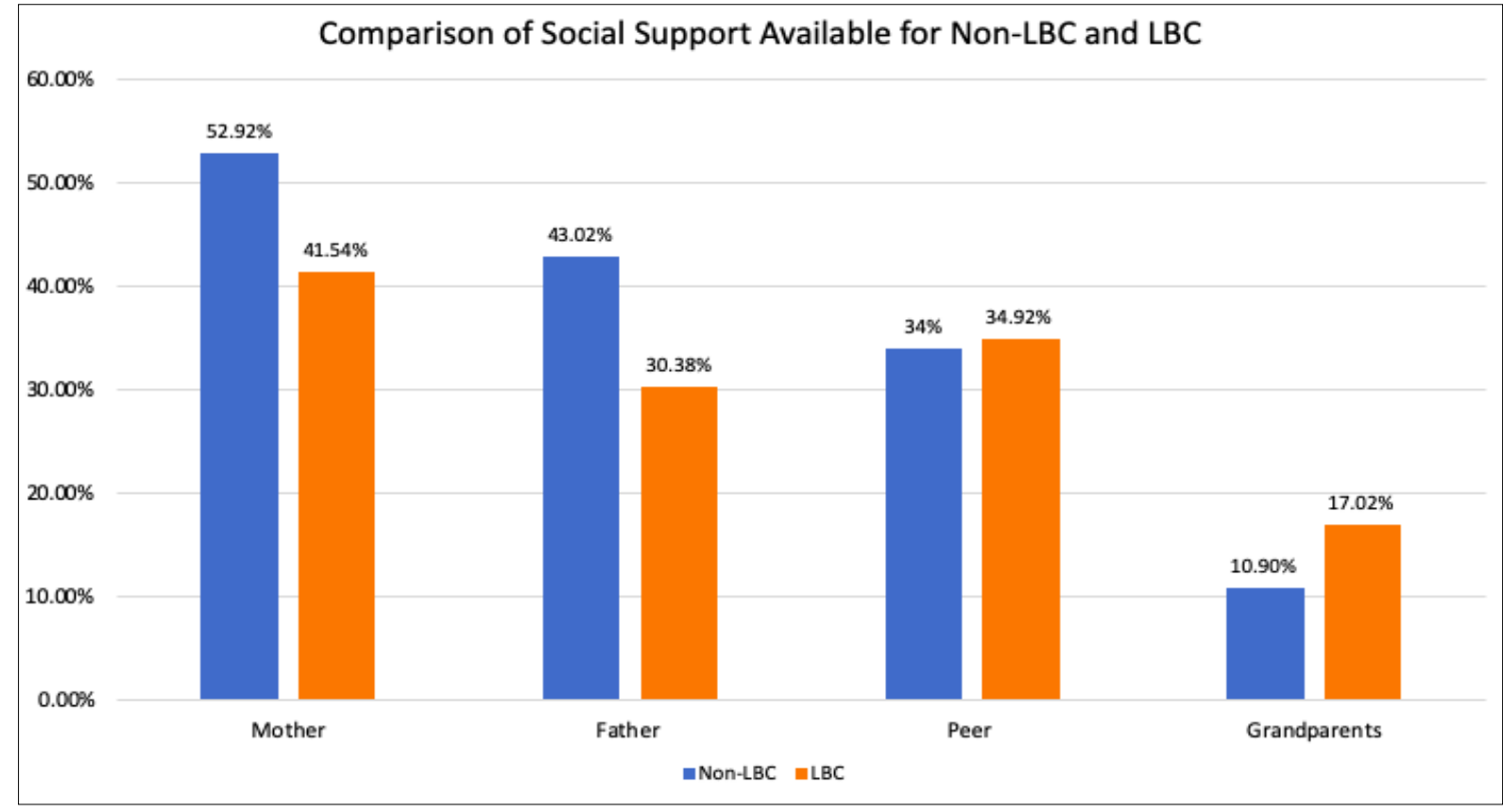

Figure3.1. Comparison of social support available for Non-LBC and LBC (Zhang et al, 2015)

Negative Experiences and Perceptions of LBC

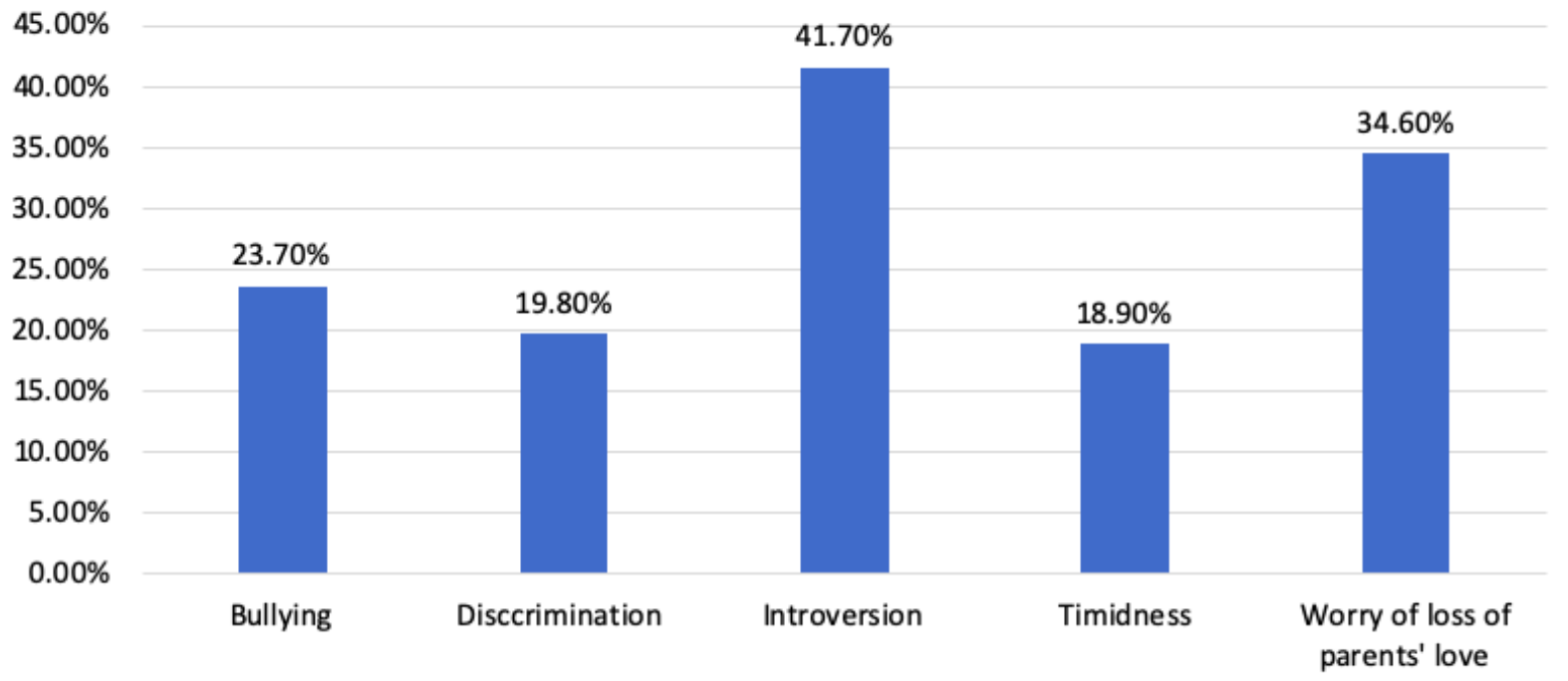

Figure3.2. Negative experiences and perceptions of LBC (Zhang et al, 2015)

\section{Grandparents Prove Unskilful in Dealing with Psychological Issues}

Parenting quality deeply affects the psychological health of children (Scott, 2012). Because of the deep-rooted Confucianist culture in China which values the family as the fundamental basis of society and encourages family cohesion, migrant parents normally entrust their children to their grandparents in Yunnan (Song et al, 
Analysis of how Family and School Conditions of Left-behind Children in Yunnan Province, China Affect their Psychological Health

2018). A survey suggested that left-behind children raised by their-grandparents is the most common familial structure (33.53\%) among all surveyed family structures in which left-behind childrenlive (Wu et al, 2015).This phenomenon corresponds to the $7 \%$ increase in grandparental support indicated in Table 2. One common issue found in this parenting structure is the separation of "teaching" from "raising" as well as the overemphasis on children's material needs. As a result, behavioral education and psychological guidance is often neglected (Mei, 2014). Grandparents who act as the children's surrogate caregivers in Yunnan province are usually not highly educated. Most possess onlyan elementary educational or even less (Xiao et al, 2019) and many grandparents in Yunnan only speak the local dialect or minority language. Due to the enormous paradigm shift in Chinese society, brought about by multiple revolutions in the $20^{\text {th }}$ century, the authority of family elders has greatly diminished. Grandparents interviewed in a survey conducted in Kunming, the capital city of Yunnan, acknowledged that they were aware that their rudimentary educational background could lead toun acceptable behaviours and attitudes being adopted by their grandchildren. Therefore they were cautious or hesitant in instructing and criticizing their grandchildren, and insisted that the responsibility of inculcation should still be shouldered by LBC's parents (Mei, 2014). Moreover, the insurmountable generation gap and deteriorating physical conditions inevitably prevent the elderly from having deeper conversations than mundane daily dialogues with their grandchildren. They aresimply not in the position totake care of their grandchildren's mental health. Often, LBCs subsequently develop a sense of emotional detachment from their grandparents which is detrimental to their psychological health, asit has been proven that perceived intimacy with one's caregiver is one of the most important factors positively correlated to resilience in left-behind children (Xiao et al, 2019). Despite some considerable benefits of being raised by grandparents, who are more experienced in attending to children's physical needs, the psychological development of children left to be nurtured by grandparents in Yunnan may be undermined by the compromised parenting skills of their grandparents, who are complete novices in caring for the children's emotional needs.

\section{Inherent Conflict in Transnational Marriages}

Yunnan province ison China's frontier, neighboring three Southeast Asian countries, and has 25 counties situated along the 4,060-kilometer border line. Transnational marriages have been a typical phenomenon for centuries and for the past few years they see an observably rapid rising tendency, largely attributable to the widening gap in economic developments on the two sides of the border. The inflow of foreigners is predominantly characterized by single women (Lu, 2017) who come from destitute families and arenot well educated. Despite marrying Chinese nationals, they are not granted Chinese nationality; nor are they registered on the household registration system, which prevents this marginalized group from enjoying state subsidies orgetting legal jobs (Yan, 2018). Local males, on the other hand, consider foreign women coming from neighboring countries as subordinate alternatives to local females and in this regard, men who have to marry foreign women are usually economically disadvantaged. Being the sole breadwinner of the family forces them to leave their wives and children behind and seek jobs with higher pay in China's bustling cities. For the left-behind children from families of transnational marriage, their mothers' background takes a toll on their development in intangible ways, even though the provincial government has revised the law to grant children of transnational marriages identity cards as long as one of the parents is a Chinese national. This is an encouraging policy, as granting children Chinese ids was unavailable until 2014. (Yin, 2017).. The most significant issues involving LBCs growing up with a non-Chinese mother is that they seldom receive necessary academic assistance (Yan, 2018). These children have low self-esteem because of familial poverty and, in some cases, they are subject to outright exclusion, discrimination and slander (Yang et al 2015). All these factors are exacerbated by the fact that chances of upward mobility and inching out of the vicious cycle of poverty seem depressingly slim. The social stigma that left-behind children are burdened with, in addition to the lack of adequate familial resources, indisputably leads to declining psychological health. 
Analysis of how Family and School Conditions of Left-behind Children in Yunnan Province, China Affect their Psychological Health

\section{School Environment}

Most left-behind children in Yunnan are at the beginning of their nine-year compulsory schooling. China's Compulsory Education Law stipulates that education is a right to be safeguarded by the state and community. Yet, the quality of education received by LBC in impoverished rural areas in Yunnan could unintentionally lead to the decline in their mental health, because underfunded schools in Yunnan face difficulties in upgrading supportive infrastructure and retaining qualified teachers. It appears that teachers currently working in rural Yunnan are either negligent in taking care of left-behind children's psychological health, or uncapable of designing and conducting effective psychological lessons and counselling.

\section{Shortage of Infrastructure and Resources}

One issue that rural schools in Yunnan have to grapple with is the shortage of financial funding for infrastructure essential to improving children's physical and psychological health. Physical health positively contributes to mental health and hence exercising is an important way for the psycho-therapeutic effect of enhanced physical health to materialize (Yin, 2013). In addition, research statistically supports that recreational activities significantly enhance students' psychological health by eliminating anxiety and encouraging self-awareness and self-control (Yuan, 2013). Inunder-resourced rural schools in Yunnan which most left-behind children attend, educational resources are of severe scarcity. The shortage of financial appropriation for purchasing educational materials and upgrading school recreational infrastructure, including libraries, sports facilities and counselling rooms, has become a norm. With constrained resources and finite shared space, left-behind children are denied the chance to relax, socialize and seek psychological counselling. Schools are also incapable of implementing enrichment classes and entertainment activities for the student body, like sporting activities and talent shows, which are commonplace among urban students. Only $23.9 \%$ students agree that infrastructure for psychological counselling, including consulting rooms, is available in their schools, and merely $6 \%$ of students have utilized these facilities (Zhang et al, 2015). Therefore, financial shortages in rural schools in Yunnan could deprive leftbehind children of means to improve their psychological health.

\section{Lack of Qualified Psychological Teachers and Counsellors}

The sense of loneliness resulting from the absence of parents can adversely affect left-behind children's mental health, but teachers, to some extent, can offset the harm incurred (Pan, 2014). However, due to the shortage of monetary resources in rural schools in Yunnan, there persists lack of qualified psychological counselors. In the 2000s, to avoid wasting educational resources, the China Ministry of Education launched a policy to assemble rural students by closing and merging rural schools, given that the number of school-aged students decreased by $24.3 \%$ from 1998 to 2007(Qin et al, 2016). For example, the number of primary schools in Jinuo Mountain County, Jinghong City in Yunnan, fell from 18 to 7 (Li, 2017). Even though the policy was officially terminated in 2012, some closed schools were not reopened becausethe local government maintained the shutdown of schools to trim the municipal budget. The consequences of budgetary austerity has resultedin an exponential swell in class sizes in the new schools, placing tremendous pressure on the teachers(China Labour Bulletin, 2019). Low salaries for teachers in rural areas only aggravate the situation. Similar to other provinces, there are two main categories of teachers in Yunnan: the state-paid teachers who earn a regular monthly salary comparable to civil servants in state-owned enterprises, and the community-paid teachers who are paid by the local government from its fiscal revenue (State University). Many rural teachers in Yunnan are community-paid teachers, who earn roughly one third the pay of their non-rural counterparts and may regularly be deprived of pensions and other bonuses (China Labour Bulletin, 2019). Therefore, rural schools find it virtually impossible to hire and retain professional teachers who study psychology or are qualified for psychological consultation. Teachers who remain in rural areas of Yunnan, already frustrated with massive work stress and low income, tend to emphasize students' quantitative academic performance and fail to look after their emotional needs. 
Analysis of how Family and School Conditions of Left-behind Children in Yunnan Province, China Affect their Psychological Health

Left-behind children who are defiant, delinquent and rebellious can easily be overlooked. Consequentially, teachers' negligence pushes them deeper down the abyss of disobedience and mental problems. On top of that, the structural shortage of teachers, including qualified teachers capable of providing psychological counselling, leave children, especially LBCs, with inadequate, middle-aged teachers to whom they are less inclined to confide their emotional issues. Hence left-behind children's mental health could worsen without prompt intervention.

\section{Flawed Psycho-Education Projects and Lessons}

Notwithstanding the fact that there are indeed some schools that provide lessons and launch programs concerning psychological health, they are, in essence, not effective in bringing forward genuine improvement in left-behind children's emotional health. For instance, the activities implemented, such as lectures and the distribution of brochures, are short-termand superficial in nature. Furthermore, since teachers in rural schools in Yunnan have not systematically studied psychology as mentioned above, they may misunderstand the standard for mental health education and confuse it with students' abnormal conduct. Some teachers apply conventional pedagogic skills in teaching their students mental health, altering the process of mental health education into mechanic absorption of psychological information (Li, 2017), which is totally irrelevant to its well-intended purpose of improving children's, and particularly left-behind children's mental conditions.

\section{CONCLUSION}

This paper suggests that inherent conflicts in both family and school could exert unfavourable influence on left-behind children's psychological conditions in a multitude of ways, resulting in a larger structural problem. However, despite the plethora of obstacles faced by left-behind children in in rural environments, their conditions are not without improvements. There are policies and regulations recently passed to safeguard the rights of LBCs. The provincial government in Yunnan is actively implementing schemes to provide allowances to students (Qin et al, 2016). Furthermore, children from families of transnational marriage are now granted nationality as mentioned earlier. Moreover, non-governmental organisations including On the Way to School and Heart to Heart are constantly advocating for left-behind children in Yunnan.

There is broad consensus that left-behind children will become a critical portion of China's future workforce. Investment in this deprived group will prove not only rewarding in the build-up of human capital, but also conducive to continuous economic growth in less developed frontier regions in China, especially in the face of an impending silver tsunami against which China is not yet fully armed to fight.

\section{REFERENCE}

1. Migrant Workers and Their Children." China Labour Bulletin. China Labour Bulletin, May 2019. https:// clb.org.hk/content/migrant-workers-and-their-children.

2. Report on China's Migrant Population Development. Beijing: China Population Publishing Company, 2016.

3. "Report of One-Percent NationalSample Census 2015."China National Bureau of Statistics, April 20, 2016. http://www.stats.gov.cn/tjsj/zxfb/201604/t20160420_1346151.html.

4. “Child Psychology." Encyclopædia Britannica. Encyclopædia Britannica, inc., September 13, 2012. https:// www.britannica.com/science/child-psychology.

5. Wang, Jun, and Jingfang She. "A Comparative Analysis on Mental Health of Left-behind Children in Minority Areas." A Comparative Analysis on Mental Health of Left-behind Children in Minority Areas, August 2019, 19-23. https://doi.org/ 1009-3907( 2019) 08-0019-05.

6. Zhang, Shiping, Zhongxiao Cong, Guo Li, and Ling He. Childrens Survival and Development in China: Data and Analysis. Beijing: China Women Publishing House, 2016. 
Analysis of how Family and School Conditions of Left-behind Children in Yunnan Province, China Affect their Psychological Health

7. Shi Yaojiang, Yu Bai, Yanni Shen, Kaleigh Kenny, and Scott Rozelle. "Effects of Parental Migration on Mental Health of Left-behind Children: Evidence from Northwestern China." China \& World Economy 24, no. 3 (2016): 105-22. https://doi.org/10.1111/cwe.12161.

8. Zhang, Xudong, Xia Zhao, and Hongyan Sun. "Survey of the Survival Condition of Left-Behind Children in Rural China." The Paper, June 11, 2015. http://m.thepaper.cn/newsDetail_forward_1340812.

9. Dong, Zesong, and Dajun Zhang. "Study on the Resilience of the Left-behind Children in Minority Nationality Regions in Yunnan Province." Chinese Journal of Child Health Care 21 (September 2013): 920-22. https:// doi.org/1008-6579(2013)09-0920-03.

10. Du, Ping, Ping Liu, and Na Zuo. "Investigation Report on Rural Left-behind Children in Yunnan." Investigation Report on Rural Left-behind Children in Yunnan, 2018. https://wenku.baidu.com/view/31c9791c81eb62 94dd88d0d233d4b14e84243efb.html.

11. Gao, Yujuan, Yu Bai, Yue Ma, and Yaojiang Shi. "Parental Migration's Effects on the Academic and NonAcademic Performance of Left-Behind Children in Rural China." China Economist 14, no. No.5 (2019): 6780. https://doi.org/1 0.19602/j .chinaeconomist.2019.9.07.

12. Zhou, Zongkui, Xiaojun Song, Ya Liu, and Dongming Zhou. "The Psychological Development and Educational Problem of Rural Left-behind Children." Journal of Beijing Normal University, no. 1 (2005): 71-79. https:// doi.org/1002-0209(2005)01-0071-09.

13. Xiao, Yuanyuan, Yeying Wang, Wei Chang, Ying Chen, Zhen Yu, and Harvey A. Risch. "Factors Associated with Psychological Resilience in Left-behind Children in Southwest China." Asian Journal of Psychiatry 46 (2019): 1-5. https://doi.org/10.1016/j.ajp.2019.09.014.

14. Fei, Xiaotong. The Institutions for Reproduction. the Commercial Press, 2008.

15. Meyrose, Ann-Katrin, FionnaKlasen, Christiane Otto, Gabriela Gniewosz, Thomas Lampert, and Ulrike Ravens-Sieberer. "Benefits of Maternal Education for Mental Health Trajectories across Childhood and Adolescence." Social Science \& Medicine 202 (2018): 170-78. https://doi.org/10.1016/j.socscimed. 2018.02.026.

16. “White Paper on Mental State of Left-behind Children 2017." Sina News. China Youth News, July 21, 2017. http://news.sina.com.cn/c/2017-07-22/doc-ifyihmmm8038563.shtml.

17. Ning, Ning, 2017.

18. Scott, Stephen. “Parenting Quality and Children's Mental Health." Current Opinion in Psychiatry 25, no. 4 (2012): 301-6. https://doi.org/10.1097/yco.0b013e328354a1c5.

19. Song, Jingjing, Chensen Ma, Chuanhua Gu, and Bin Zuo. "What Matters Most to the Left-Behind Children's Life Satisfaction and School Engagement: Parent or Grandparent?" Journal of Child and Family Studies 27, no. 8 (2018): 2481-90. https://doi.org/10.1007/s10826-018-1086-4.

20. Wu, Zhihui, and Jingmei Li. "The Investigation Report of Survival Status for Left-behind Children in Rural Areas." China Agricultural University Journal of Social Sciences Edition 32, no. 1 (February 2015): 65-74. https://doi.org/10.13240/j.cnki.caujsse.20150123.004.

21. Mei, Pengchao, 2014.

22. Xiao, Yuanyuan, Ying Chen, Wei Chang, Yiqi Pu, Xue Chen, Jieyun Guo, Yuting Li, and Fang Yin. "Perceived Social Support and Suicide Ideation in Chinese Rural Left-behind Children: A Possible Mediating Role of 
Analysis of how Family and School Conditions of Left-behind Children in Yunnan Province, China Affect their Psychological Health

Depression." Journal of Affective Disorders 261 (2020): 198-203. https://doi.org/10.1016/j.jad. 2019.09. 081.

23. Lu, Haifa. "Characteristics, Dynamics and Impacts of Transnational Marriage - Based Immigrants in the Perspective of Borderland Administration: A Case Study in Two Border Counties of Yunnan Province." Journal of Yunnan Minzu University (Social Sciences) 34, no. 5 (September 2017): 62-70. https:// doi.org/10.13727/j.cnki.53-1191/c.2017.05.011.

24. Yan, Zhengshuai, 2018.

25. Yin, Liang, 2017.

26. Yang, Guocai, and Yuqiao Shi. "Transnational Marriages at the Bordering Countries and Its Prospect." Journal of Beifang University of Nationalities, no. 3 (2015): 118-25.

27. Yin, Shaofeng. "Research on the Relationship between Community Residents' Physical Activities and Psychological Health ." Sports Culture Guide, no. 8 (August 2013): 38-55.

28. Yuan, Jiaxiang. "Relationship between Frequent Recreational and Physical Activities and Undergraduates' Psychological Health Conditions." Science \& Technology Information, no. 18 (2013).

29. Pan, Feng, 2014.

30. Qin, Guifen, Xingyu Chen, and Ying Qin. "Conflicts between Isolation and Modern: Analyzing the Education Predicament of Ethnic Minority Areas with Less Population in Yunnan Province." Journal of Kunming Metallurgy College 32, no. 4 (August 2016): 100-104.

31. Li, Zhongyang, 2017.

32. "China - Teaching Profession." StateUniversity.com. Accessed January 3, 2020. https://education.stateuniversity. com/pages/277/China-TEACHING-PROFESSION.html.

Citation: Wei Cai. "Analysis of how Family and School Conditions of Left-behind Children in Yunnan Province, China Affect their Psychological Health". American Research Journal of Humanities and Social Sciences, vol 6, no. 1, 2020, pp. 1-10.

Copyright (C) 2020 Wei Cai. This is an open access article distributed under the Creative Commons Attribution License, which permits unrestricted use, distribution, and reproduction in any medium, provided the original work is properly cited. 